www.nature.com/jhg

\title{
Polymorphisms and allele frequencies of the $A B O$ blood group gene among the Jomon, Epi-Jomon and Okhotsk people in Hokkaido, northern Japan, revealed by ancient DNA analysis
}

\author{
Takehiro Sato $^{1}$, Hisako Kazuta ${ }^{1}$, Tetsuya Amano ${ }^{2}$, Hiroko Ono ${ }^{2}$, Hajime Ishida ${ }^{3}$, Haruto Kodera ${ }^{4}$, \\ Hirofumi Matsumura ${ }^{5}$, Minoru Yoneda ${ }^{6}$, Yukio Dodo ${ }^{7}$ and Ryuichi Masuda ${ }^{1}$
}

\begin{abstract}
To investigate the genetic characteristics of the ancient populations of Hokkaido, northern Japan, polymorphisms of the $A B O$ blood group gene were analyzed for 17 Jomon/Epi-Jomon specimens and 15 Okhotsk specimens using amplified product-length polymorphism and restriction fragment length polymorphism analyses. Five ABO alleles were identified from the Jomon/ Epi-Jomon and Okhotsk people. Allele frequencies of the Jomon/Epi-Jomon and Okhotsk people were compared with those of the modern Asian, European and Oceanic populations. The genetic relationships inferred from principal component analyses indicated that both Jomon/Epi-Jomon and Okhotsk people are included in the same group as modern Asian populations. However, the genetic characteristics of these ancient populations in Hokkaido were significantly different from each other, which is in agreement with the conclusions from mitochondrial DNA and $A B C C 11$ gene analyses that were previously reported. Journal of Human Genetics (2010) 55, 691-696; doi:10.1038/jhg.2010.90; published online 12 August 2010
\end{abstract}

Keywords: $A B O$ blood group; allele frequency; ancient DNA; Epi-Jomon people; Jomon people; Okhotsk people

\section{INTRODUCTION}

The $A B O$ blood group is one of the classical genetic markers that are useful for studying the genetic relationships between populations. In the $A B O$ blood group system discovered by Landsteiner, ${ }^{1}$ determinants of $A$ and $B$ antigens are $A$ and $B$ transferases that are encoded by $\mathrm{A}$ and $\mathrm{B}$ alleles, respectively, at the single $A B O$ blood group locus on human chromosome $9,{ }^{2}$ whereas the product of the $\mathrm{O}$ allele has neither A nor B transferase activities. ${ }^{3}$

Among various local populations in Japan and neighboring regions, different frequencies of the $A B O$ blood group have been reported by many studies. ${ }^{4-18}$ In these studies, however, allele frequencies of the $A B O$ blood group gene were inferred by the maximum-likelihood method on the basis of immunological data, because the molecular genetic basis of $A B O$ blood types was unknown at that time.

Recent studies have revealed that the $A B O$ blood group gene possesses a high degree of polymorphisms at the molecular level ${ }^{19}$ and that allele frequencies of the $A B O$ gene are different among various populations. ${ }^{20-26}$ Therefore, allele frequencies and distributions of the $A B O$ gene can be appropriate indices for investigating the genetic relationships between populations. In this study, to further understand the history and genetic features of human populations in
Hokkaido, northern Japan, polymorphisms of the $A B O$ gene in the Jomon/Epi-Jomon and Okhotsk people who lived in Hokkaido were investigated.

On the Hokkaido island, cultures different from those of Honshu (mainland of the Japanese archipelago) have developed after the Jomon period (about 12000-2400 years BP). ${ }^{27}$ The Yayoi culture with the rice culturing was not introduced to Hokkaido, and the Epi-Jomon (third century BC to seventh century AD), Satsumon (eighth to thirteenth centuries) and Ainu cultures (since the fourteenth century) developed in Hokkaido. ${ }^{27}$ In addition, the Okhotsk culture was developed around coastal regions of the Okhotsk Sea from the Epi-Jomon period to the Satsumon period. ${ }^{28}$

Recent analyses of ancient DNA revealed that genetic features of the Jomon/Epi-Jomon people of Hokkaido were considerably different from those of the Okhotsk people. Adachi et al. ${ }^{29,30}$ reported that mitochondrial DNA (mtDNA) haplogroups $\mathrm{N} 9 \mathrm{~b}$ and D1 were major in the Jomon people of Hokkaido and that they had a close genetic affinity to the Udegey of the continental Far East. By contrast, Sato et al. ${ }^{31,32}$ demonstrated that mtDNA haplogroups Y, G1b and N9b were major in the Okhotsk people and that they were genetically closely related to modern local populations in Sakhalin and lower

${ }^{1}$ Graduate School of Science, Hokkaido University, Sapporo, Japan; ${ }^{2}$ Hokkaido University Museum, Sapporo, Japan; ${ }^{3}$ Faculty of Medicine, University of the Ryukyus, Nishihara, Japan; ${ }^{4}$ School of Dental Medicine, Tsurumi University, Yokohama, Japan; ${ }^{5}$ Sapporo Medical University, Sapporo, Japan; ${ }^{6}$ Graduate School of Frontier Sciences, University of Tokyo, Kashiwa, Japan and ${ }^{7}$ Tohoku University School of Medicine, Sendai, Japan

Correspondence: Dr R Masuda, Graduate School of Science, Hokkaido University, North 10, West 8, Kita-ku, Sapporo 060-0810, Japan.

E-mail: masudary@ees.hokudai.ac.jp

Received 11 March 2010; revised 31 May 2010; accepted 24 June 2010; published online 12 August 2010 
regions of the Amur River, including the Ulchi, Nivkhi and Negidal. Moreover, Sato et al. ${ }^{33}$ revealed that allele frequencies of the ABCC11 gene, which is an autosomal gene associated with earwax phenotypes (wet/dry), were significantly different between the Jomon/Epi-Jomon and Okhotsk people. The Jomon people had a relatively higher frequency of the wet allele, showing genetic characteristics similar to those of the Ainu. On the other hand, the frequency of the wet allele in the Okhotsk people is relatively low, indicating genetic features similar to modern populations of northeastern Asia.

In this study, we examined polymorphisms of the $A B O$ blood group gene using an amplified product-length polymorphism (APLP) analysis of ancient DNA to further understand genetic features of the Jomon/Epi-Jomon people and the Okhotsk people in Hokkaido. On the basis of comparisons of the allele frequencies among ancient and modern populations, we discuss the genetic features and history of ancient populations of Hokkaido.

\section{MATERIALS AND METHODS}

\section{Sample collection}

To determine genotypes of the $A B O$ blood group gene in the ancient populations in Hokkaido, 81 skeletal remains of the Jomon and Epi-Jomon people and 50 skeletal remains of the Okhotsk people, excavated from 26 archeological sites in Hokkaido and Sakhalin (Figure 1), were analyzed. Each site was classified into Jomon, Epi-Jomon or Okhotsk culture by using archeological analyses based on earthenware, stone implements, traces of houses and strata. The skeletal remains were preserved at the Hokkaido University Museum, Sapporo Medical University and Tohoku University School of Medicine. To avoid a duplicate analysis of skeletal remains from single individuals, parts in the same positions of bones or bones from different graves within one archeological site were sampled.

\section{Contamination precautions}

The following standard contamination precautions were taken: separation of pre- and post-PCR experimental areas, use of gloves, face masks and laboratory coats, use of disposable filter-plugged pipette tips and disposable tubes,

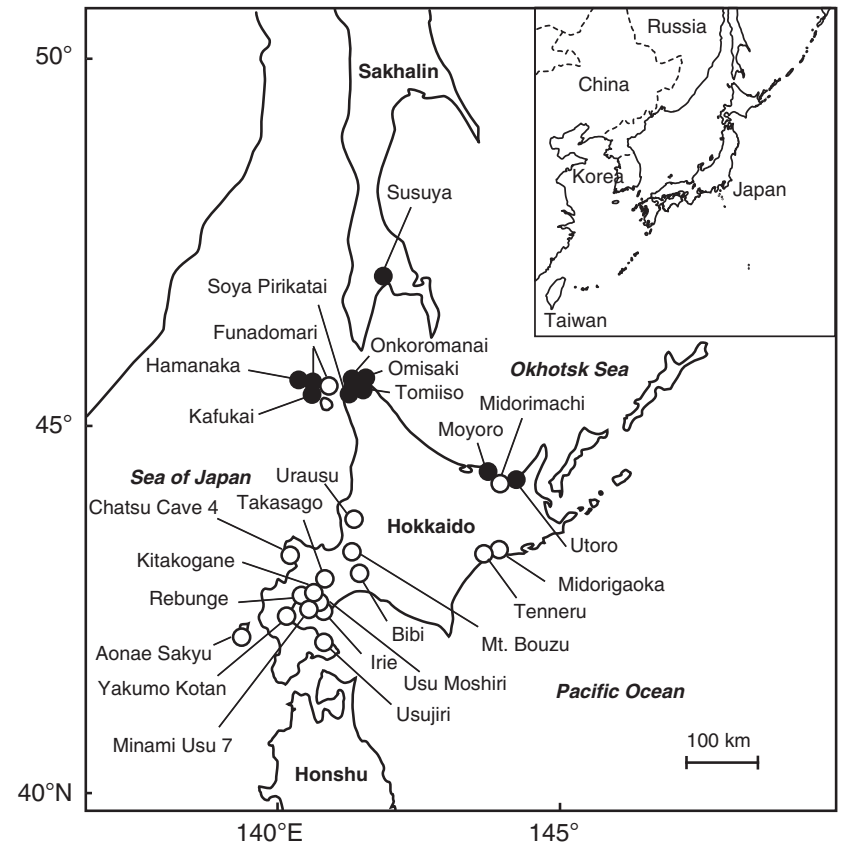

Figure 1 Geographical locations of archaeological sites of the Jomon/EpiJomon culture (open circles) and Okhotsk culture (closed circles) from which specimens analyzed in this study were excavated. treatment with DNA-AWAY (Molecular BioProducts, San Diego, CA, USA), ultraviolet irradiation of equipments and bench, negative extraction controls and negative PCR controls.

\section{DNA extraction}

Total DNA was extracted from femurs, ribs, coxal bones, skulls, sacrums or teeth of ancient skeletal remains sampled, according to the following methods. ${ }^{31-34}$ To avoid surface contamination of external DNA, each bone or tooth was soaked in sodium hypochlorite solution (Nacalai Tesque, Kyoto, Japan) for $5 \mathrm{~min}$, rinsed with DNase-/RNase-free distilled water and air-dried. Samples were then powdered with a standard dental drill. Approximately $0.2-0.5 \mathrm{~g}$ of bone powder per specimen was decalcified with $30 \mathrm{ml}$ of $0.5 \mathrm{M}$ ethylenediaminetetraacetic acid in a 50-ml plastic tube, with rotating at room temperature for $24 \mathrm{~h}$. Decalcified pellets were suspended in $5 \mathrm{ml}$ of $0.5 \mathrm{M}$ ethylenediaminetetraacetic acid containing $100 \mu \mathrm{l}$ of proteinase $\mathrm{K}$ concentrated at $10 \mathrm{mg} \mathrm{ml}^{-1}$ and incubated overnight at $37^{\circ} \mathrm{C}$ with rotation. The solution was extracted using the phenol-chloroform extraction method (phenol-chloroform-isoamyl alcohol 25:24:1). ${ }^{35}$ The extracts were concentrated into approximately $100 \mu \mathrm{l}$ of TE buffer using VivaSpin 6 Concentrators (Sartorius Stedim Biotech, Goettingen, Germany) and used as a template for subsequent PCR.

APLP and PCR-restriction fragment length polymorphism analyses To analyze polymorphisms of the $A B O$ blood group gene of ancient specimens, APLP analysis ${ }^{36}$ was conducted. For high accuracy of PCR amplification, APLP analysis was separated into three PCR reactions (set A using primers 1-4, set B using primers 5-7 and set $C$ using primers $8-10$ ). The PCR amplification was carried out in a reaction mixture of $20 \mu \mathrm{l}$ containing reagents of the Multiplex PCR Kit (Qiagen, Hilden, Germany), optimum concentrations of each primer ${ }^{36}$ and $0.4 \mu \mathrm{g}^{-1}$ of bovine serum albumin $\left(20 \mathrm{mg} \mathrm{ml}^{-1}\right.$; Roche, Basel, Switzerland). The PCR conditions were $95^{\circ} \mathrm{C}$ for $15 \mathrm{~min}$, followed by 40 cycles of $94^{\circ} \mathrm{C}$ for $30 \mathrm{~s}$, $54^{\circ} \mathrm{C}$ for $3 \mathrm{~min}, 72^{\circ} \mathrm{C}$ for $90 \mathrm{~s}$ and the final extension at $72{ }^{\circ} \mathrm{C}$ for $10 \mathrm{~min}$.

An aliquot of $10 \mu \mathrm{l}$ of the PCR product was separated by electrophoresis in a $13 \mathrm{~cm}$ native polyacrylamide gel $(10 \% \mathrm{~T}, 5 \% \mathrm{C}, \mathrm{T}=$ acrylamide+methylenebisacrylamide/acrylamide+methylenebisarcylamide+water, $\mathrm{C}=$ methylenebisacrylamide/ acrylamide+methylenebisacrylamide) containing $375 \mathrm{~mm}$ of Tris-NaOH buffer ( $\mathrm{pH}$ 8.9) with running buffer ( $12.5 \mathrm{~mm}$ Tris, $96 \mathrm{~mm}$ glycine; $\mathrm{pH}$ 8.3). The DNA bands were detected with an ultraviolet illuminator after staining with ethidium bromide.

A new allele that has not been reported in the previous studies $22,23,25,36,37$ might be generated by the recombination. In this study, however, we surmised that no new alleles were generated by recombination and we used only the results from the APLP genotyping ${ }^{36}$ (Figure $2 \mathrm{a}$ ).

To distinguish allele $A B O^{*} A 101$ from $A B O^{*} A 102$, PCR-restriction fragment length polymorphism (RFLP) analysis was carried out for specimens having $A^{1}$ allele because only $A B O^{*} A 102$ does not possess a NaeI restriction site in exon 7 (Figure $2 \mathrm{~b}$ ). The DNA fragment including a single-nucleotide polymorphism, $467 \mathrm{C} \rightarrow \mathrm{T}$, defining allele $A B O^{*} A 102$ was amplified with the two primers newly designed in this study: ABO-RFLP1 (5'-AAGCACTTCATGGTGGGCCA-3') and ABO-RFLP2 (5'-GACAGCTGCCGACCGGTC-3'). After PCR amplification, an aliquot of $8.8 \mu \mathrm{l}$ of PCR products was digested with NaeI in the reaction mixture containing $1 \times$ buffer and 2 units of restriction enzyme at $37^{\circ} \mathrm{C}$ for $3 \mathrm{~h}$. The digested DNA was electrophoresed on the native polyacrylamide gel and detected by the same method as that of the APLP analysis (Figure 2b).

The APLP and PCR-RFLP analyses for each bone sample were carried out three times to assess the reproducibility of the analytical results. Samples from which the reproducibility was not obtained were excluded from the subsequent statistical analysis.

\section{Statistical analysis}

To check for any possibilities of external DNA contamination, the HardyWeinberg equilibrium test for genotypic data of the Jomon/Epi-Jomon people and the Okhotsk people that were obtained in this study was conducted using GENEPOP version 4.0 (http://genepop.curtin.edu.au/). ${ }^{38,39}$ Allele frequencies of the $A B O$ gene locus were estimated by direct counting, and compared with previously reported data from modern populations such as East Asia, Europe 
a

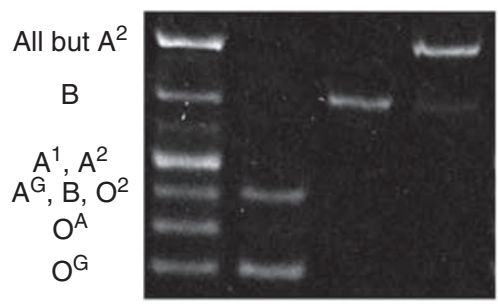

$B / O^{G}$

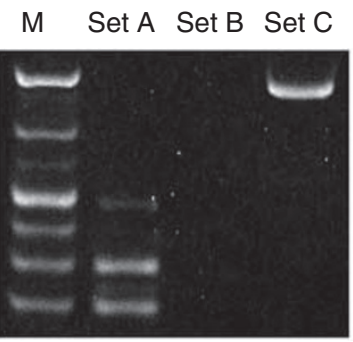

$\mathrm{O}^{\mathrm{A}} / \mathrm{O}^{\mathrm{G}}$

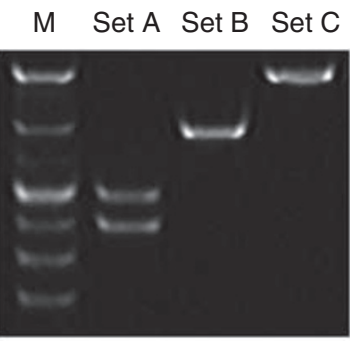

$A^{1 / B}$

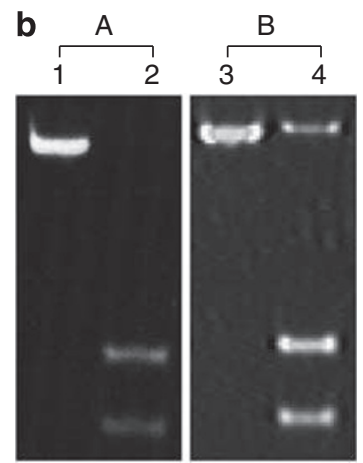

Figure 2 Electrophoresis images of the amplified product length polymorphism (APLP) (a) and restriction fragment length polymorphism (RFLP) (b) analyses. (a) Sets A, B and C are products of PCR reactions with primers $1-4,5-6$ and $8-10,36$ respectively. (b) Lanes 1 and 3 show PCR products before digestion with Nael, whereas lanes 2 and 4 indicate PCR products after digestion with Nael. Sample A possesses allele $A B 0^{*} A 101$ and sample B has allele $A B O * A 102$.

and Oceania: 340 Japanese, ${ }^{22} 43$ Han, 37 Kazakh, 59 Uygur, ${ }^{23} 57$ Balopa, 69 Gidra, 34 Tongan $^{25}$ and 169 German. ${ }^{37}$ On the basis of $A B O$ allele frequencies obtained, principal component $(\mathrm{PC})$ analysis was also performed to examine the genetic affinities among 10 populations using STATISTICA version 06J (Statsoft Japan).

\section{RESULTS}

The DNA fragments including the single-nucleotide polymorphisms in the $A B O$ gene exons 6 and 7 were successfully PCR-amplified, and genotyped from 8 of 42 Jomon, 3 of 39 Epi-Jomon and 13 of 50 Okhotsk specimens (Table 1). In this study, because the numbers of successfully genotyped individuals was small in the Jomon and EpiJomon specimens, these were regarded together as the Jomon/EpiJomon people. No successful results were obtained from the remaining samples because of possible DNA degradation. Departure from Hardy-Weinberg equilibrium was not observed in either Jomon/ Epi-Jomon or Okhotsk people $(P>0.05)$.

Table 2 shows allele frequencies of the $A B O$ gene in the Jomon/EpiJomon and Okhotsk people obtained in this study, compared with those of other populations cited from previous studies. The Jomon/ Epi-Jomon and Okhotsk people shared five alleles (Tables 1 and 2), all of which were previously reported to be present in modern Japanese people. ${ }^{23,36}$ The predominant allele in the Jomon/Epi-Jomon people was $A B O^{\star} O 102$, whereas that in the Okhotsk people was $A B O^{\star} O 101$. Allele frequencies of the $A$ and $B$ groups in the Jomon/Epi-Jomon people were slightly higher than those in modern Japanese, and that of the $O$ group in the Jomon/Epi-Jomon people was slightly lower than that of modern Japanese (Table 2). Allele $A B O^{\star} A 102$, which has been detected as a predominant $A$ allele in East Asian populations (0.197 in Japanese ${ }^{22}$ and 0.186 in $\operatorname{Han}^{23}$ ), was observed in both Jomon/ Epi-Jomon (0.182) and Okhotsk people (0.038), whereas the frequency of $A B O^{*} A 101$ in Jomon/Epi-Jomon people was higher than
Table 1 Genotypes of the $A B O$ blood group gene of the Jomon/ Epi-Jomon and Okhotsk specimens

\begin{tabular}{|c|c|c|c|}
\hline Specimen no. & Archeological site & Genotype & Phenotype \\
\hline \multicolumn{4}{|l|}{ Jomon people } \\
\hline $\mathrm{JM}-1$ & Funadomari & $A 101 / B 101$ & $A B$ \\
\hline JM-2 & Funadomari & 0101/0102 & 0 \\
\hline JM-3 & Funadomari & B101/0102 & $B$ \\
\hline $\mathrm{JM}-4$ & Funadomari & A101/0101 & $A$ \\
\hline JM-5 & Funadomari & 0102/0102 & 0 \\
\hline JM-6 & Funadomari & A101/B101 & $A B$ \\
\hline $\mathrm{JM}-7$ & Usujiri & A102/A102 & $A$ \\
\hline $\mathrm{JM}-8$ & Funadomari & A102/0102 & $A$ \\
\hline \multicolumn{4}{|c|}{ Epi-Jomon people } \\
\hline EPJ-1 & Usu Moshiri & A102/0102 & $A$ \\
\hline EPJ-2 & Usu Moshiri & B101/B101 & $B$ \\
\hline EPJ-3 & Chatsu Cave 4 & 0101/0102 & 0 \\
\hline \multicolumn{4}{|l|}{ Okhotsk people } \\
\hline $\mathrm{OKH}-1$ & Moyoro & $0101 / 0101$ & 0 \\
\hline $\mathrm{OKH}-2$ & Utoro & A102/0101 & $A$ \\
\hline OKH-3 & Omisaki & B101/0102 & $B$ \\
\hline $\mathrm{OKH}-4$ & Omisaki & $0101 / 0101$ & 0 \\
\hline OKH-5 & Omisaki & B101/0102 & $B$ \\
\hline OKH-6 & Omisaki & A101/0101 & $A$ \\
\hline OKH-7 & Hamanaka & B101/0102 & $B$ \\
\hline OKH-8 & Hamanaka & 0101/0102 & 0 \\
\hline OKH-9 & Hamanaka & 0101/0101 & 0 \\
\hline OKH-10 & Hamanaka & 0101/0102 & 0 \\
\hline OKH-11 & Hamanaka & 0101/0102 & 0 \\
\hline OKH-12 & Pirikatai & B101/0102 & $B$ \\
\hline OKH-13 & Tomiiso & 0102/0102 & 0 \\
\hline
\end{tabular}


Table 2 Allele frequencies of the $A B O$ blood group gene in ancient populations of Hokkaido, and Asian, European and Oceanic populations

\begin{tabular}{|c|c|c|c|c|c|c|c|c|c|}
\hline \multirow[b]{2}{*}{ Population } & \multicolumn{9}{|c|}{ ABO alleles } \\
\hline & A101 & A102 & A201 & A (Total) & B101 & 0101 & 0102 & 0201 & O (Total) \\
\hline Okhotsk $(2 n=26)$ & 0.038 & 0.038 & 0.000 & 0.076 & 0.154 & 0.423 & 0.346 & 0.000 & 0.769 \\
\hline Japanese $(2 n=680)$ & 0.069 & 0.197 & 0.000 & 0.266 & 0.190 & 0.293 & 0.247 & 0.000 & 0.540 \\
\hline Han $(2 n=86)$ & 0.023 & 0.186 & 0.000 & 0.209 & 0.186 & 0.337 & 0.267 & 0.000 & 0.604 \\
\hline Balopa $(2 n=114)$ & 0.079 & 0.193 & 0.000 & 0.272 & 0.097 & 0.491 & 0.140 & 0.000 & 0.631 \\
\hline Gidra $(2 n=138)$ & 0.232 & 0.000 & 0.000 & 0.232 & 0.080 & 0.659 & 0.029 & 0.000 & 0.688 \\
\hline Tongan $(2 n=68)$ & 0.029 & 0.250 & 0.000 & 0.279 & 0.088 & 0.574 & 0.059 & 0.000 & 0.633 \\
\hline German $(2 n=338)$ & 0.213 & 0.000 & 0.077 & 0.290 & 0.047 & 0.426 & 0.216 & 0.021 & 0.663 \\
\hline
\end{tabular}

Data of Japanese, ${ }^{22}$ Han, ${ }^{23}$ Kazakh, ${ }^{23}$ Uygur, ${ }^{23}$ Balopa, ${ }^{25}$ Gidra, ${ }^{25}$ Tongan $^{25}$ and German ${ }^{37}$ populations are cited from previous studies.

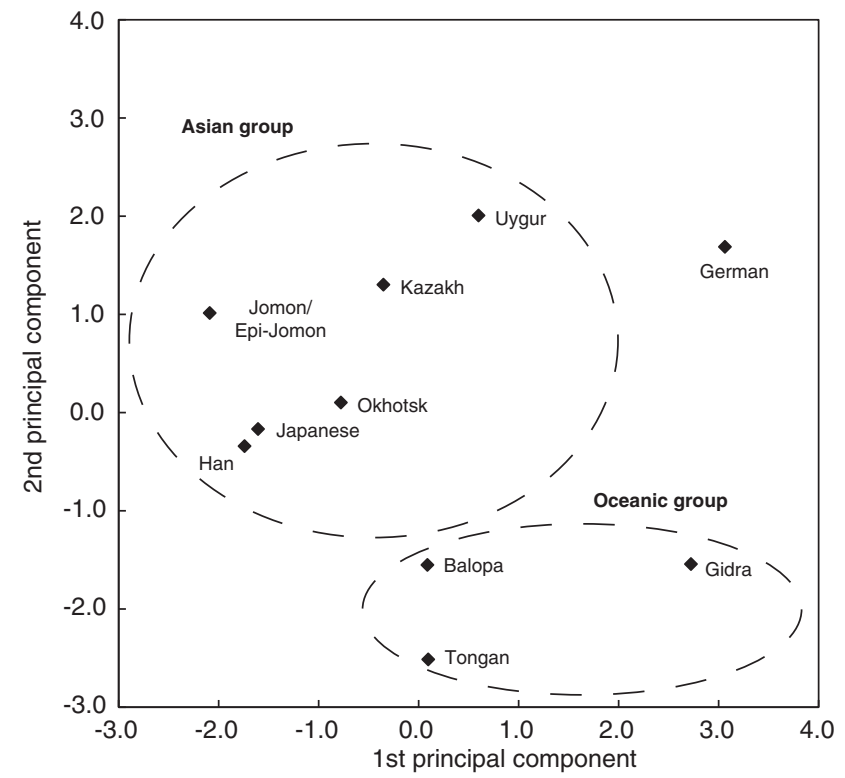

Figure 3 Genetic relationships among the 10 populations determined on the basis of principal component analysis of $A B O$ allele frequencies. Data of Japanese, ${ }^{22}$ Han, $^{23}$ Kazakh, ${ }^{23}$ Uygur, ${ }^{23}$ Balopa, ${ }^{25}$ Gidra, ${ }^{25}$ Tongan $^{25}$ and German ${ }^{37}$ populations are cited from previous studies.

that of modern East Asian populations such as Japanese and Han (Table 2). The frequencies of subtypes of the $O$ group in the Jomon/ Epi-Jomon people were considerably different from those of modern Japanese. Within the Jomon/Epi-Jomon people, the frequency of $A B O^{\star} O 101$ (0.136) was significantly lower than that of $A B O^{\star} O 102$ (0.318). Frequencies of $A B O^{\star} O 101$ and $A B O^{\star} O 102$ among $O$ alleles (individual frequency against 0.454 as total ' $O$ ' frequency) in Jomon/ Epi-Jomon people were $30.0 \%(0.136 / 0.454)$ and $70.0 \%(0.318 / 0.454)$, respectively (see Table 2 ). By contrast, those in modern Japanese were $54.3 \%(0.293 / 0.540)$ and $45.7 \%(0.247 / 0.540)$, respectively. In the Okhotsk people, $76.9 \%$ of $A B O$ alleles consisted of $A B O^{\star} O 101$ and $A B O^{\star} O 102$, indicating that the allele frequencies were specifically different from those of other East Asian populations.

Figure 3 shows the result of the PC analysis for the 10 populations. Analyzed populations were roughly separated into three groups: Asian, European and Oceanic groups, and the Jomon/Epi-Jomon people and Okhotsk people were included in the Asian group.
The modern Japanese population was located nearer Han rather than near the Jomon/Epi-Jomon people (Figure 3). Although the Jomon/Epi-Jomon and Okhotsk people were distributed in Hokkaido, they were located far from each other in the Asian group (Figure 3). Allele $A B O^{\star} B 101$ showed the highest contribution rate to the PC 1 (24.6\%) and allele $A B O^{\star} O 201$ showed the highest contribution rate to the PC $2(23.4 \%)$ through the 10 populations.

\section{DISCUSSION}

This study first revealed polymorphisms of the $A B O$ blood group gene in ancient populations of Hokkaido. All five $A B O$ alleles detected in this study were observed in both Jomon/Epi-Jomon and Okhotsk people (Tables 1 and 2). Allele $A B O^{\star} A 102$ is the predominant allele among the $A$ group in East Asian populations. Frequencies of $A 101$ and $A 102$ are $2.3 \%$ and $18.6 \%$ in Han and $6.9 \%$ and $19.7 \%$ in Japanese, respectively. ${ }^{22,23} A B O^{*} A 102$, which is the most common allele in East Asia, was observed in both the Jomon/Epi-Jomon and Okhotsk people analyzed in this study. Results indicate that it is reasonable that the Jomon/Epi-Jomon and Okhotsk people had the characteristics of the $A B O$ blood group gene that is common to Asian populations.

Among $O$ alleles of the Jomon/Epi-Jomon people, the frequency (0.318) of $A B O^{*} O 102$ included in the $O^{\mathrm{G}}$ group, which possesses the $\mathrm{A} \rightarrow \mathrm{G}$ mutation in nucleotide position 297 , was remarkably higher than that (0.136) of $A B O^{\star} O 101$ included in the $O^{\mathrm{A}}$ group, which does not possess the mutation in that position (Table 2). Nakamura ${ }^{40}$ reported that a gentle gradation of $O$ allele frequencies was seen across the Japanese archipelago: the higher frequency of the $O^{\mathrm{A}}$ group was observed in central parts of Japan such as Gifu and Mie Prefectures, whereas the higher frequency of the $O^{\mathrm{G}}$ group was observed in northern and southern parts of Japan, such as Akita, Okinawa and Kagoshima Prefectures. It is generally considered that the modern Japanese population was formed by two distinct populations (Neolithic Jomon people and Aeneolithic Yayoi immigrants), and gene flow from the Asian continent by migration of the Yayoi people strongly influenced the native population in the central part of the Japanese archipelago, and hardly influenced those in northern and southern parts of the Japanese archipelago such as Hokkaido and Okinawa. ${ }^{41}$ These findings suggest that the $O^{\mathrm{G}}$ group is the predominant $O$ allele in the Neolithic Jomon people who were native to the Japanese archipelago, and that the $O^{\mathrm{A}}$ group was the predominant $O$ allele in the Aeneolithic Yayoi people who were immigrants to the Japanese archipelago from the Asian continent between the third 
century $\mathrm{BC}$ and the third century $\mathrm{AD}$. To verify this hypothesis, molecular genetic information on polymorphisms of the $A B O$ gene for the Jomon and Yayoi people in Honshu and Ainu in Hokkaido is required.

Among the Okhotsk people, $76.9 \%$ of $A B O$ alleles consisted of members of the $O$ group. On the basis of morphological ${ }^{42-45}$ and mtDNA data, ${ }^{31,32}$ the Okhotsk people could have originated from the Sakhalin Island and from lower regions of the Amur River in East Siberia. This indicates that the frequency of $O$ alleles among ancestors of those populations might have been high. Otherwise, it is likely that the high frequency of $O$ alleles detected in the Okhotsk people was caused by founder effects through the migration to northeastern coastal regions of Hokkaido. The future investigation on polymorphisms of the $A B O$ gene among modern populations native to Sakhalin and lower regions of the Amur River could provide an insight into unveiling the history of establishment of people around the Okhotsk Sea.

The PC analysis of allele frequencies (Figure 3) indicated that the ancient populations of Hokkaido analyzed in this study were apparently included into the Asian group. In addition, it showed that the population genetically closest to modern Japanese was Han, and not the Jomon/Epi-Jomon people. This suggests that the allele frequencies of the $A B O$ gene in modern Japanese were strongly influenced by gene flow from the Asian continent caused by immigration of Aeneolithic Yayoi people. In this study, however, only the Jomon/Epi-Jomon people in Hokkaido were examined. Future analyses of the $A B O$ gene for the Jomon people in Honshu would clarify the effects of gene flow of the Aeneolithic Yayoi people.

As most of the mtDNA haplogroups identified in the Jomon/EpiJomon people of Hokkaido were common to those of eastern Siberian people, the Jomon/Epi-Jomon people of Hokkaido might have been strongly affected by gene flow from northeastern Asian populations. ${ }^{29,30}$ Similarly, morphological and genetic studies indicate that the Okhotsk people could have originated from eastern Siberia as well. . $^{31,32,42-45}$ The Jomon/Epi-Jomon and Okhotsk people were, however, located far from each other, as shown in the PC analysis (Figure 3). Although the Jomon/Epi-Jomon people and Okhotsk people shared the five alleles, the frequencies were considerably different from each other. The mtDNA haplogroup distributions of the Jomon/Epi-Jomon ${ }^{29,30}$ and Okhotsk people ${ }^{32}$ are also different from each other. In addition, allele frequencies of the earwax gene $A B C C 11$ in those people were significantly different from each other. ${ }^{33}$ These findings strongly show that Jomon/Epi-Jomon and Okhotsk people have characteristics that are different from each other in mitochondrial (maternal) and autosomal (biparental) gene pools, in addition to the classical morphological differences.

Although the Ainu (modern indigenous people in Hokkaido) could have been established by genetic mixtures between direct descendants of the Neolithic Jomon and Okhotsk people, ${ }^{31-33}$ gene flow from the Okhotsk people to the Ainu was not tested in this study because the previous data of the $A B O$ blood group for the Ainu are of an immunological nature and show only frequencies of the $A, B$ and $O$ groups; that is, frequencies of subtypes of the $A, B$ and $O$ groups for the Ainu are not available. To further understand the history of populations in Hokkaido, it is important to clarify the polymorphisms of the $A B O$ blood group gene in the Ainu for comparison with those of the Jomon/Epi-Jomon and Okhotsk people.

\section{ACKNOWLEDGEMENTS}

We thank Dr Ryosuke Kimura (University of the Ryukyus) for his helpful comments on the paper. This study was supported in part by Grants-in-Aid-for
Scientific Research (Nos. 21401023, 20-1887) from the Japan Society for the Promotion of Science (JSPS), and by the grant from the Suhara Memorial Foundation. The first author (TS) is a JSPS Research Fellow.

1 Landsteiner, K. Zür Kenntnis der antifermentativen, lytischen und agglutinierenden Wirkungen des Blutseruns und der Lymphe. Z. Bakteriol. 27, 357-362 (1900).

2 Yamamoto, F., McNeill, P. D. \& Hakomori, S. Genomic organization of human histoblood group ABO genes. Glycobiology 5, 51-58 (1995).

3 Dungern, E. V. \& Hirschfeld, L. Ueber Vererbung gruppenspezifischer Strukturen des Blutes, II. Z. Immun. Exp. Ther. 1, 284-292 (1910).

4 Akaishi, S., Murakami, S., Jin, H., Nishikawa, F., Okazaki, Y., Kudo, T. et al. Studies on the distribution of the $A B O$ blood groups in the population of northern Japan. Hirosaki Med. J. 10, 594-605 (1959) (in Japanese).

5 Fujiki, N., Yamamoto, M., Takenaka, S., Ishimaru, T., Takanashi, T., Sugimito, N. et al. A study of inbreeding in some isolated populations. Jpn. J. Hum. Genet. 12, 205-225 (1968).

6 Inagaki, M. $A B O$ and $Q$ blood type in Nagoya city. Jpn. J. Legal Med. 7, 222-223 (1953).

7 Iseki, S., Masaki, S., Furukawa, K., Mohon, I., Lambert, R. M. \& Rosamilia, H. G. Diego and Miltenberger blood factor in Japanese. Gumma J. Med. Sci. 7, 120-126 (1958).

8 Kobayashi, C. Statistical studies on the distribution of $A B O$ blood groups in Japan. XI. Synthesis. Hanzaigaku Zasshi 14, 727-735 (1940) (in Japanese).

9 Kobayashi, H. On the blood groups of the inhabitants at Tsushima and Iki island. Jpn. J. Legal Med. 6, 153 (1952) (abstract in Japanese).

10 Kobayashi, H. On the blood groups of the Tokachi Ainu. Jpn. J. Legal Med. 7, 223 (1953) (abstract in Japanese).

11 Kobayashi, H. On the blood groups of the Iburi Ainu. Jpn. J. Legal Med. 10, 325-326 (1956) (abstract in Japanese).

12 Kobayashi, H. \& Okada, K. Racial biological studies of the inhabitants in Tanegashima. Jpn. J. Legal Med. 8, 288 (1954) (abstract in Japanese).

13 Nakajima, H., Ohkura, K., Shen, Y. Z., Chow, Z. S., Lee, S. P., Orita, Y. et al. The distribution of several serological and biochemical traits in East Asia. I. The distributions of $A B O, M N, Q$, Lewis and Rh blood groups in Taiwan. Jpn. J. Hum. Genet. 11, 244-251 (1967).

14 Noda, K. \& Hayakawa, Z. The frequency of the $R h$ groups in Japanese random blood. Proceedings of the Eighth Congregation of the International Society of Blood Transfusion, Tokyo (1962) (abstract).

15 Terada, K., Kajitani, K., Kotoku, S., Tanaka, Y. \& Fujitani, Y. Report on blood groups of the Oki islanders. Jpn. J. Legal Med. 10, 325 (1956) (abstract in Japanese).

16 Terawaki, T., Hirayama, T., Imamura, M., Hamada, K., Yoahii, I., Arata, H. et al. Clinicogenetic study on an isolated Island (Ikema Is.) in Okinawa Prefecture. Shonika-Shinryo 35, 1467-1475 (1972) (in Japanese).

17 Yamamoto, M., Wada, T., Watanabe, T., Kanazawa, H., Saito, R., Kondo, M. et al. Genetic polymorphisms in four isolated communities in Kinki district. Jpn. J. Hum. Genet. 17, 273-285 (1972).

18 Yoshinari, K., Nishikawa, K., Hori, A. \& Inokuma, T. Results of the bloodtyping tests I one group in Tokyo. Jpn. J. Legal Med. 19, 216 (1965) (abstract in Japanese).

19 Yip, S. P. Sequence variation at the human ABO locus. Ann. Hum. Genet. 66, 1-27 (2002).

20 Ogasawara, K., Bannai, M., Saitou, N., Yabe, R., Nakata, K., Takenaka, M. et al. Extensive polymorphism of $A B O$ blood group gene: three major lineages of the alleles for the common $A B O$ phenotypes. Hum. Genet. 97, 777-783 (1996).

21 Olsson, M. L., Santos, S. E., Guerreiro, J. F., Zago, M. A. \& Chester, M. A. Heterogeneity of the $O$ alleles at the blood group $A B O$ locus in Amerindians. Vox Sanguinis 74, 46-50 (1998).

22 Kobayashi, K., Iwasaki, M., Anan, K., Suzuki, Y., Suzuki, H., Tamai, S. et al. An analysis of polymorphisms for the $A B O$ blood group genes in a Japanese population based on polymerase chain reaction. Anthropol. Sci. 107, 109-121 (1999).

23 Iwasaki, M., Kobayashi, K., Suzuki, H., Anan, K., Ohno, S., Geng, Z. et al. Polymorphism of the $A B O$ blood group genes in Han, Kazakh and Uygur populations in the Silk Route of northwestern China. Tissue Antigens 56, 136-142 (2000).

24 Roubinet, F., Kermarrec, N., Despiau, S., Apoil, P. A., Dugoujon, J. M. \& Blancher, A. Molecular polymorphisms of $O$ alleles in five populations of different ethnic origins. Immunogenetics 53, 95-104 (2001).

25 Ohashi, J., Naka, I., Ohtsuka, R., Inaoka, T., Ataka, Y., Nakazawa, M. et al. Molecular polymorphisms of $A B O$ blood group gene in Austronesian and non-Austronesian populations in Oceania. Tissue Antigens 63, 355-361 (2004).

26 Ohashi, J., Naka, I., Kimura, R., Tokunaga, K., Yamaguchi, T., Natsuhara, K. et al. Polymorphisms in the $A B O$ blood group gene in three populations in the New Georgia group of the Solomon Island. J. Hum. Genet. 51, 407-411 (2006).

27 Yamanouchi, S. Cultures of antiquity in Japan after the Jomon culture (epilogue). Dolmen 2, 49-53 (1933) (in Japanese).

28 Amano, $T$. in Epi-Jomon and Okhotsk cultures (eds Nomura, T. \& Utagawa, H.) 110-113 (Hokkaido Shimbun, Sapporo, 2003) (in Japanese)

29 Adachi, N., Sakaue, K., Dodo, Y., Shinoda, K., Umetsu, K. et al. Mitochondrial DNA analysis of the Jomon and Epi-Jomon skeletons in Hokkaido, Japan (second report). DNA Polymorph. 14, 86-90 (2006) (in Japanese). 
30 Adachi, N., Shinoda, K., Umetsu, K. \& Matsumura, H. Mitochondrial DNA analysis of Jomon skeletons from the Funadomari site, Hokkaido, and its implication for the origins of Native American. Am. J. Phys. Anthropol. 138, 255-265 (2009).

31 Sato, T., Amano, T., Ono, H., Ishida, H., Kodera, H., Matsumura, H. et al. Origins and genetic features of the Okhotsk people, revealed by ancient mitochondrial DNA analysis. J. Hum. Genet. 52, 618-627 (2007).

32 Sato, T., Amano, T., Ono, H., Ishida, H., Kodera, H., Matsumura, H. et al. Mitochondrial DNA haplogrouping of the Okhotsk people based on analysis of ancient DNA: an intermediate of gene flow from the continental Sakhalin people to the Ainu. Anthropol. Sci. 117, 171-180 (2009)

33 Sato, T., Amano, T., Ono, H., Ishida, H., Kodera, H., Matsumura, H. et al. Allele frequencies of the $A B C C 11$ gene for earwax phenotypes among ancient populations of Hokkaido, Japan. J. Hum. Genet. 54, 409-413 (2009).

34 Masuda, R., Amano, T. \& Ono, H. Ancient DNA analysis of brown bear (Ursus arctos) remains from the archeological site of Rebun Island, Hokkaido, Japan. Zool. Sci. 18, 741-751 (2001).

35 Sambrook, J., Fritsch, E. F. \& Maniatis,, T Molecular Cloning: A Laboratory Manual 2nd edn (Cold Spring Harbor Laboratory Press, New York, 1989).

36 Watanabe, G., Umetsu, K., Yuasa, I. \& Suzuki, T. Amplified product length polymorphism (APLP): a novel strategy for genotyping the $A B O$ blood group. Hum. Genet. 99, 34-37 (1997).
37 Nishimukai, H., Okiura, T., Shinomiya, T., Fukumori, Y., Ohnoki, S., Shibata, H. et al. Genotyping of the $A B O$ blood group system: analysis of nucleotide position 802 by PCR-RFLP and distribution of $A B O$ genotypes in a German population. Int. J. Legal Med. 109, 90-93 (1996).

38 Raymond, M. \& Rousset, F. GENEPOP (version 1.2): population genetics software for exact tests and ecumenicism. J. Hered. 86, 248-249 (1995).

39 Rousset, F. Genepop'007: a complete reimplementation of the Genepop software for windows and Linux. Mol. Ecol. Resour. 8, 103-106 (2008).

40 Nakamura, T. (2008) Analysis and application of polymorphisms in the $A B O$ blood group gene by PCR-SSCP method. Tsukuba Univ. Tech. Rep. 28, 39-44 (2008) (in Japanese).

41 Hanihara, K. Dual structure model for the population history of Japanese. Jpn. Rev. 2, 1-33 (1991).

42 Ishida, H. Morphological studies of Okhotsk crania from Omisaki, Hokkaido. J. Anthropol. Soc. Nippon 96, 17-45 (1988).

43 Ishida, H. Metric and nonmetric cranial variation of the prehistoric Okhotsk people. Anthropol. Sci. 104, 233-258 (1996).

44 Kozintsev, A. G. Prehistoric and recent populations of Japan: multivariate analysis of cranioscopic data. Arctic Anthropol. 29, 104-111 (1992).

45 Komesu, A., Hanihara, T., Amano, T., Ono, H., Yoneda, M., Dodo, Y. et al. Nonmetric cranial variation in human skeleton remains associated with Okhotsk culture. Anthropol. Sci. 116, 33-47 (2008). 